\title{
Capturing Debriefing and Enhancing Reflection within Simulated Clinical Learning Environments
}

\author{
*Mark Wareing ${ }^{a}$, Jacqueline A. England ${ }^{a}$, David Mathew ${ }^{b}$, Carla Ball ${ }^{a}$, Amanda \\ Willetts $^{a}$, Jane Kemp ${ }^{a}$, Kelly Clifford ${ }^{a}$, Andrea Thompson ${ }^{a}$, Ian Dove ${ }^{c}$, \& Louise Adams ${ }^{a}$ \\ a: University of Bedfordshire, United Kingdom; b: Herts Valleys Clinical Commissioning Group, \\ United Kingdom; c: Bedfordshire Hospitals NHS Foundation Trust, United Kingdom
}

\begin{abstract}
This article presents findings from an evaluation of a new A3-size learner notes sheet designed for use by healthcare students engaging in clinical simulation and clinical skills sessions. The notes sheet consists of an adapted form of the SBAR (situation, background, assessment, response) tool, whilst capturing post-simulation oral debriefing provided by a facilitator. Additionally, the Driscoll (2007) model is used to provide students with an opportunity to reflect on their engagement in clinical simulation. Two cohorts of students, who engaged in separate simulation sessions, completed the A3 sheet. The study featured 33 midwifery and 21 operating department practitioner (ODP) students undertaking a simulation. Documentary analysis was undertaken to identify the depth of reflective writing of both groups of students. Midwifery student participants reflected on their experiences of simulation at a slightly deeper level than their ODP counterparts. All students adhered to the structure of the notes sheet when receiving their briefing from the facilitator and when asked to write their reflective accounts. This study has sought to explore an under-researched area of clinical simulation: the extent to which healthcare students can utilise reflection when engaging with a clinical scenario within a simulated learning environment.
\end{abstract}

Keywords: depth of reflection; reflective writing; simulation

\section{Introduction}

University campus clinical skills and simulation suites provide healthcare students with a safe environment to learn and refine clinical skills, particularly when presented with a simulated learning scenario based on the care of a notional patient. There has been little consideration of the relationship between the briefing that students receive prior to the start of the simulated scenario; the value of the

*Corresponding Author: Dr Mark Wareing, Director of Practice Learning, University of Bedfordshire, Faculty of Health \& Social Sciences, School of Healthcare Practice, Aylesbury Campus, Mary Seacole Building, Stoke Mandeville Hospital, HP21 8AL, United Kingdom Email: mark.wareing@beds.ac.uk

Journal URL: https://publications.coventry.ac.uk/index.php/pblh

Wareing, M., England, J. A., Mathew, D., Ball, C., Willetts, A., Kemp, J., Clifford, K., Thompson, A., Dove, I., \& Adams, L. (2020). Capturing debriefing and enhancing reflection within simulated clinical learning environments. International Journal of Practice-based Learning in Health and Social Care, 8(1), 47-59. https://doi.org/10.18552/ijpblhsc.v8i1.565

\section{cc)(i) $\odot$}

CY NC ND ( 2020 Mark Wareing, Jacqueline A England, David Mathew, Carla Ball, Amanda Willetts, Jane Kemp, Kelly Clifford, Andrea Thompson, Ian Dove, \& Louise Adams. This Open Access article is distributed under the terms of the Creative Commons Attribution Attribution-Non-Commercial No Derivatives 4.0 International License (https://creativecommons.org/licenses/by-nc-nd/4.0/), which permits unrestricted non-commercial use, distribution, and reproduction in any medium, provided the original work is properly cited and is unaltered. 
debriefing provided by the facilitator; learner reflection; and whether development needs can be identified by students following the simulated experience.

This article presents findings from a study into a new A3-size clinical skills and clinical simulation learner notes sheet developed by staff from the Bedfordshire Education Skills, Simulation \& Training (BESST) centre at the University of Bedfordshire. The notes sheet was used to facilitate clinical simulation sessions provided for pre-registration midwifery and operating department practitioner (ODP) students. It is argued that the notes sheet creates a synergy between the pre-briefing and debriefing stages of simulation to stimulate reflective writing and support students' professional development planning.

\section{Literature review}

Within the literature, debriefing and reflection appear to be discussed interchangeably with studies suggesting a strong relationship between the need for structured debriefing and reflection to enhance students' clinical reasoning and decision-making whilst engaging in clinical simulation activities. Although it is recognised that healthcare students may experience performance anxiety whilst engaging in simulation (Alinier, 2003; Muldoon et al., 2014), the overall educational value of simulation in terms of the development of communication skills and confidence is suggested within empirical studies and is a key element of social cognitive orientations to learning.

The provision of clinical simulation sessions may vary with students being exposed to a clinical scenario utilising a manikin, an educator, paid 'actor' or even a student playing the role of a patient. For example, Bucknall et al.'s (2016) article explored the decision-making of 97 nursing students and identified eleven types of decisions made by students working within three Australian simulation centres. Scenarios of eight minutes' duration were utilised and featured an actor simulating acute heart failure. In contrast, Mackey et al.'s (2014) study, involving fifteen nursing students, explored the value of students playing the role of a standardised patient during simulation. The findings suggested that student nurses' knowledge and observation skills are enhanced, particularly when students evaluated the practice of both their own and their fellow students, as it gave them new insight into what it feels like to be the person receiving nursing care, particularly with regard to the effect of verbal and non-verbal communication. It could be argued that using students in the role of a standardised patient may lead other learners to interpret the behaviour of the patient as relevant to the scenario, when it could be irrelevant or even misleading. The use of manikins may enhance consistency in the delivery of simulation sessions and allow for a more objective assessment of a student's clinical competency.

Cooper et al.'s (2012) systematic literature review into the evidence to support simulation in midwifery education concluded that simulation is particularly useful for developing students' understanding of labour and obstetric emergencies (although a cross comparison of approaches is almost impossible due to different curricula). As some obstetric emergencies are relatively rare the authors conclude that the utilisation of simulation is critical, both prior to and during clinical placements within a hospital setting. Similarly, Coffey (2015) undertook a literature review that suggested that the use of simulation within midwifery education programmes supports student confidence and self-efficacy, but is reliant on the quality of briefing, reflection and evaluation provided by facilitators. Coffey (2015) concluded that careful lecturer preparation and realistic simulation experiences were essential for successful and educationally effective clinical simulation provision. It was noted that reflection and debriefing were discussed interchangeably within the simulation literature. For example, debriefing and reflection required lecturers to provide a safe and supportive simulation environment where there was sufficient time for a student's performance to be analysed in response to simulations that were based on clinical reality and therefore authentic. However, the extent to which learners might engage in reflection, either during or following a simulation session, has been overlooked within studies which seem to focus on the outcome or response to a session rather than the process of students' learning during or following a session where students have engaged with a clinical scenario. Fero et al.'s (2010) study explored the critical thinking skills of 36 nursing students and revealed that $75 \%$ did not meet overall performance expectations. Effective critical thinking was evaluated through the examination of video recordings of simulated performance in order to assess students' evaluation and problem recognition, reporting of data, initiation of intervention, anticipation of medical orders, and rationale and prioritisation of decisions. The study suggested that students struggled with synthesising clinical information and lacked confidence in the reporting of their findings. Jensen's (2013) study highlighted the importance of students being given 
opportunities to self-assess their clinical reasoning behaviours and competency. In this study, 88 nursing students compared the results of a self-assessment completed by students with assessments undertaken by academic staff during a clinical reasoning evaluation that featured simulation. Interestingly, students under-assessed themselves in relation to their ability to communicate in a calm and confident manner ahead of being debriefed by facilitators. The authors argue that this finding highlights the impact of debriefing on the enhancement of students' global perception of their clinical abilities.

Only one study appears to have explored the nature of reflection and the relationship between reflective writing and the debriefing offered by facilitators at the end of a simulation session. The REsPOND model, a five-item reflective tool, was evaluated in Lavoie et al.'s (2017) study. The authors' assertion that reflection is the hallmark of debriefing was tested through a study that explored the impact of the REsPOND tool on 19 nursing students' clinical judgement. The reflective tool provided students with a framework, not only prepare for but to make sense of the patient's situation which, in turn, helped to review their observations and make logical connections during the clinical simulation. The authors concluded that a systematic approach to debriefing enhances clinical judgement.

\section{Background}

In order to place debriefing and reflection at the centre of our clinical simulation provision, three of the article's authors (MW, JAE, \& DM) devised a notes sheet (Box 1) to assist students and facilitators to embed debriefing and reflection, leading to personal development planning (through four stages) following a period of simulation or a clinical skills session:

Stage 1: It was decided to use the 'SBAR' (situation, background, action, recommendation) tool (NHS Improvement, 2018) commonly used with healthcare settings within the United Kingdom (to optimise communication between clinical staff) within the notes sheet to capture the pre-simulation briefing provided by the session facilitator;

Stage 2: Learners would capture notes from the facilitator's de-briefing following the completion of the clinical simulation scenario;

Stage 3: Learners' would write a piece of reflection after the simulation session. Having explored a range of models, Driscoll's (2007) 'what, so what, now what' reflective tool was chosen as it has a concise and simple structure;

Stage 4: Finally, the learner could use their notes and the written reflection (from the three preceding stages) to create a personal development plan.

The A3 size was chosen to replicate the large observation charts used within critical care settings, whilst the layout (Box 1) was designed to enable students to fold the sheet in half and complete each stage. A range of guidance was embedded within the notes sheet as a form of instructional scaffolding (Brush \& Saye, 2002) to assist learners to adapt SBAR to their own clinical or therapeutic context and to initiate reflective writing.

\section{Purpose of study}

This study has sought to answer the following research questions:

(1) How effective is the notes sheet in capturing pre-briefing and debriefing by students within a clinical simulation session?

(2) What is the quality of reflective writing generated by students using the notes sheet having completed a clinical simulation session?

The overall purpose of the study was to establish whether the notes sheet could capture information received during the briefing and debriefing stage of a simulated clinical learning experience based on the presentation of a clinical scenario to two different groups of healthcare students and to evaluate the quality of reflective writing arising from learners' participation in simulation. Examination of student's 
Box 1: Clinical Simulation \& Clinical Skills Notes sheet

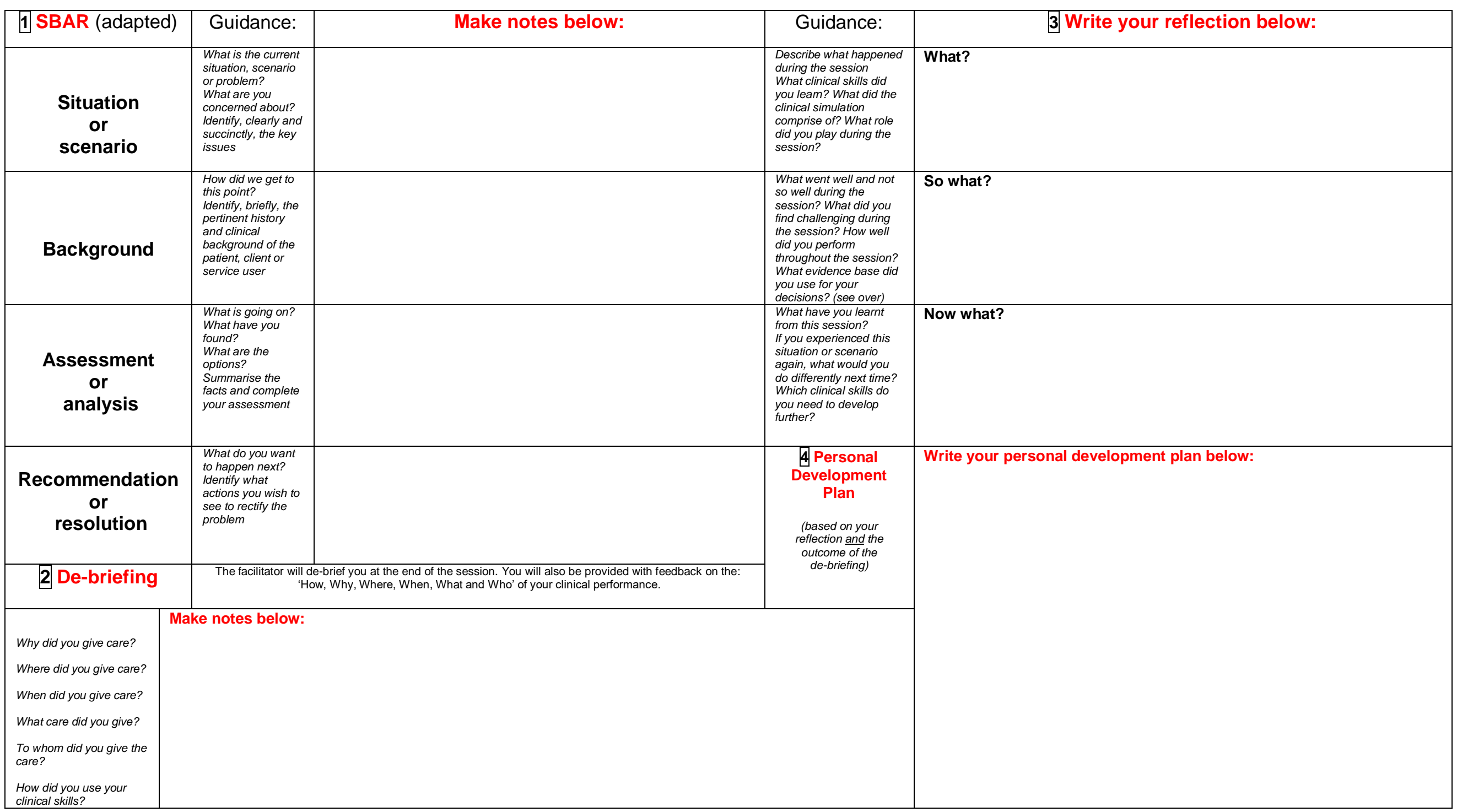


written development plans was not undertaken as a unit of analysis could not be identified. In contrast to other studies, the research did not seek to evaluate the clinical outcome of the clinical simulation sessions undertaken by the participants.

\section{Ethics}

Ethical approval for the study was obtained from the University of Bedfordshire Institute for Health Research (IHR) ethics committee. Participants had the right to withdraw from the study at any time.

\section{Research design}

An interpretivist methodology was adopted for this study where the focus was on the social world of the simulated environment and the unique, individual, qualitative perspectives actions of individuals (Crotty, 1998) as captured by students using the notes sheet.

Purposive sampling, where "information rich cases, events or settings are chosen on the basis that they provide the best perspective on the phenomenon of interest" (Gray, 2014, p. 217), was used for this research. The samples consisted of thirty-three pre-registration midwifery and twenty-one operating department practitioner students. Documentary analysis of completed notes sheets (for all students) was used for data analysis. Documentary analysis through the use of primary documents is defined as "the selection of a direct record of an event or process by a witness of subject involved" (McCulloch, 2012, p. 211). Documentary analysis was undertaken to analyse the depth of reflective writing contained within the notes sheets completed by all study participants, using Moon's (2004) levels of reflection (Box 2). Documentary analysis of the quality of learners' written reflective accounts, using levels of reflection as the unit analysis, have been used by a number of researchers (Kember et al., 2008; Orland-Barak, 2005; Plack et al., 2005; Wong et al., 1995).

Box 2: Depth levels of written reflection (ㅂatton \& Smith, 1995, adapted by Moon, 2004, p. 97)

Descriptive writing: writing that is not considered to show evidence of reflection. It is a description with no discussion beyond description.

Descriptive reflection: there is description of events. The possibility of alternative viewpoints is accepted but most reflection is from one perspective.

Dialogic reflection: the work demonstrates a 'stepping back' from events and actions leading to a different level of mulling about discourses with self and exploring the discourse of events and actions. There is a recognition that different qualities of judgement and alternative explanations may exist for the same material. The reflection is analytical or integrative, though may reveal inconsistency.

Critical reflection: demonstrates awareness that actions and events are located in and influenced by multiple historical and socio-political contexts.

Clinical scenarios were used with both the midwifery and operating department practitioner student participants. Clinical scenarios within simulation are defined as a plan of an expected and potential course of events that includes participant preparation, pre-briefing, patient information, participant objectives, equipment, role expectations, a progression outline, and debriefing. The role of the facilitator is to encourage reflective thinking and provide feedback regarding participant performance to ensure that emotions are explored and that learning is assimilated and explored in relation to future clinical situations (Meakim et al., 2013).

\section{Recruitment}

All participants were recruited to take part in the study via an announcement made on the university virtual learning environment website (BREO), where a copy of the participant information sheet and consent form could be examined and downloaded. 


\section{Participant selection}

Participants who agreed to take part in the study attended timetabled clinical skills sessions where a full explanation of the research was provided prior to the completion of consent forms. Participants had the right not to take part in the research, but were required to attend the clinical skill session. Within both studies the influence of academic staff over their own students was minimised as the clinical sessions were facilitated with the assistance of academic staff (who were members of the research team) from different pre-registration programmes.

\section{Midwifery student study}

Thirty-three first-year BSc (Hons) midwifery students took part in a clinical simulation. Participants in groups of no more than six were pre-briefed with a scenario featuring a 32-weeks' pregnant woman who presented with headache, proteinuria, pretibial oedema and a blood pressure of 170/110. The simulation ran for 30 minutes before the facilitator debriefed participants. The scenario was then repeated with a second group of students whilst the first group were taken into another room in order to write their reflection using the sheet.

\section{Data collection}

On completion of the breakaway session, the notes sheets of all participants were collected in and subsequently analysed independently by two members of the research team (MW \& DM) and recorded notes on each notes sheet against Moon's (2004) levels of reflection (Box 2). For both studies each researcher analysed $50 \%$ of each group of participant's notes sheets. Prior to the independent analysis of the notes sheets, a meeting took place to moderate a sample against each of the criteria to ensure interrater reliability of the researcher in the assessment of each notes sheet against the four levels of reflection. Additionally, documentary analysis of the notes sheets was undertaken by members of the research team who did not teach on the midwifery or operating department practitioner programmes, or who had no previous or on-going contact with the students.

\section{Documentary analysis of midwifery student reflection}

Documentary analysis was undertaken to analyse the depth of reflective writing contained within the notes sheets completed by midwifery students, who were given pseudonyms to protect their anonymity.

\section{Results}

'Descriptive writing' was considered to be writing that does not show evidence of reflection. It is a description with no discussion beyond description. One participant made comments which were very much at face value but demonstrated an awareness of what could be done in order to meet their personal learning need:
We were given a scenario with symptoms... Very nervous speaking up in session. Found I was more familiar with symptoms than the treatments. To revise more and learn more in depth on pre-eclampsia, particularly the medications and drugs used and dosages. To find out where the pre-eclampsia box is kept in Trust [Hospital] (Gemma).

Similarly, another participant's observations seemed somewhat matter-of-fact although some ideas were expressed about how learning could be progressed:

I was able to witness and think through the scenario of a woman with pre-eclampsia... drawing-up of drugs and practice delivering these. I felt I may need to know more information on the subject to be able to work thoroughly. I will read through more guidelines (Shefali).

'Descriptive reflection' was regarded as a description of events that included the possibility of alternative viewpoints being accepted, but with most reflection from one perspective. For example, one participant reflected on the application of their knowledge to the scenario including the challenge of applying 
knowledge and thinking logically as part of the management of the patient. Additionally, what needed to be learnt in relation to the particular scenario had also been identified:

I learnt how to load-up a syringe driver and about drawing-up medication and dosages of drugs utilised in this clinical scenario. I played the role of the midwife. It was good applying knowledge to a real-life situation. I found it challenging to apply knowledge 'on the spot', but made me realise I need to learn and revise more. E.g. NICE guidelines, RCOG guidelines [professional bodies]... think more logically through management, practice and more simulation, when possible in practice and amongst peers (Rosamund).

Rosamund's reflection suggests that her experience was challenging particularly when having to use knowledge in response to a critical incident. Her experience signifies that although simulation provides students with a safe clinical environment free of patient harm, students are required to respond cognitively as well as affectively and that this has an impact on self-confidence as well as levels of satisfaction (Lewis \& Ciak, 2011).

'Dialogic reflection' is regarded as work that demonstrated a 'stepping back' from events and actions leading to a 'mulling over' and deeper internal dialogue regarding the self and other actors. There is recognition that different qualities of judgement and alternative explanations may exist for the same material. Dialogic reflection is analytical or integrative, but may reveal inconsistency. Dina reflected on the overall value of the simulation opportunity and suggested ways in which simulation could be utilised again in the future. Additionally, she identified her learning needs and suggested how she might engage in simulation differently in the future:

The simulation was as realistic as it could be as the manikin did 'breathe' and have a pulse, etc. My role was as a midwife and I checked the medication with another midwife preparing magnesium sulphate. Simulation is a good way for me to learn as information is retained better. It would have been good to be able to re-do the scenarios in the future to evaluate whether any information did stick. I felt I performed well - I did check the drugs. I had to use the sheet with drug calculations to do so. I have learnt to be systematic in my approach to emergency situations. If I had to do the scenario again I would be more vocal... (Dina).

Meena described the simulation task and reflected on what had been taught about medication dosages. Additionally, thoughts about other people and how they engaged in the simulation task are reviewed in the context of an expression of personal enjoyment:

The scenario ran smoothly, everyone had their roles and worked together. As a team we remembered most of the things we needed to do; however the teaching staff were great at prompting... I've learnt how important it is that everyone knows their role in an emergency situation to get the best possible outcome - teamwork is the key. I would like to have simulation days more often as they really do prepare us for placement and real situations. I really enjoyed the simulation day and found it very interesting and beneficial to my learning. It was a great revision tool for our assessments and enabled us to understand why we do certain things (Meena).

Meena's reflection highlights the important role of facilitators in directing students (Cantrell, 2008) in order to enhance their self-efficacy (Coffey, 2015). On this occasion self-efficacy appears to have been enhanced through appropriate prompting. In Forneris et al.'s (2015) study, facilitators were given specific instruction on the nature and delivery of prompting and cueing deemed appropriate for students, which in turn strengthened standardisation within each rolling simulation. Therefore, the level of prompting and cueing given to students within a period of simulation not only supports performance, as indicated by Meena, but promotes reliability which is particularly important when simulation is used as an assessment strategy.

Overall, midwifery students demonstrated a strong ability to engage in the process of reflection. The majority of participants wrote accounts at the level of descriptive-reflective or dialogic reflection, as illustrated in the pie chart in Figure 1. 
Figure 1: Depth of reflection within notes sheets - Midwifery student study

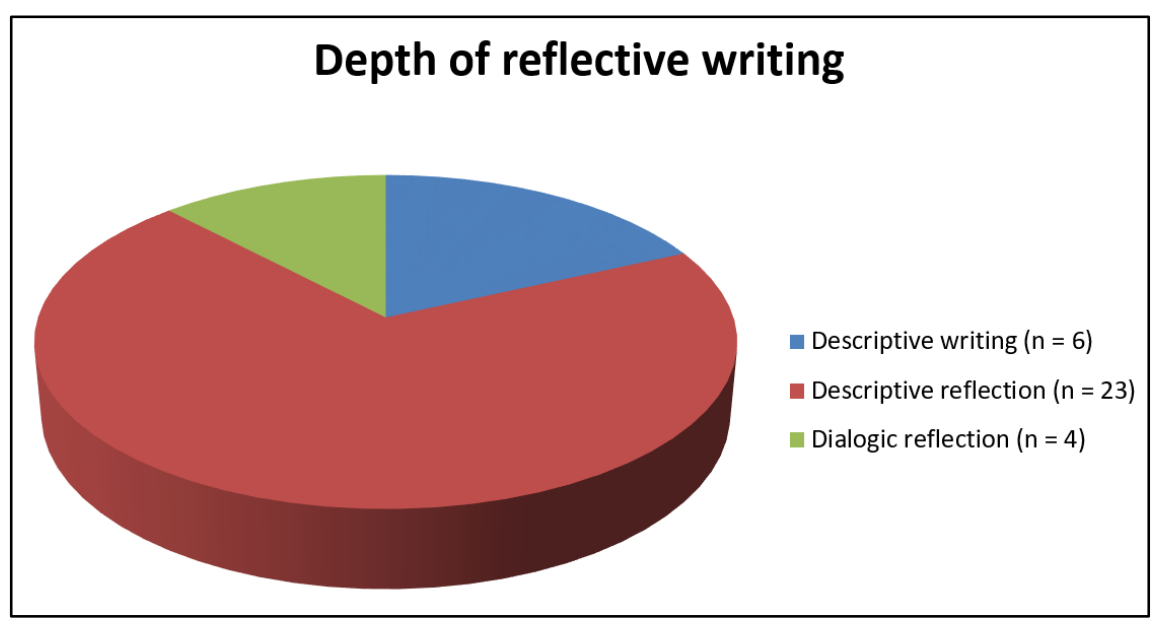

\section{Operating Department Practitioner student study}

Twenty-one second-year diploma in higher education ODP students took part in a clinical simulation. Two pairs of students (one playing an ODP; the other a standardised patient) were seated at circular tables. Students were expected to assess the patient for surgery by completing a pre-operative check list. The patient had co-morbidities (diabetes and hypertension) which required preoperative management. The simulation was run twice enabling a total of eight students who had volunteered to play either the role of the ODP or patient. The remaining students sat in an arc around each pair and used the sheets to take notes during the simulation. All students were given the opportunity to complete a notes sheet during the pre-brief, debrief and at the end of each cycle of simulation.

\section{Documentary analysis of ODP student reflection}

Documentary analysis of 42 notes sheets (generated by 21 study participants engaging in two simulation cycles) was undertaken to analyse the depth of reflective writing completed by each ODP student, using Moon's (2004) levels of reflection (Box 2). Two researchers independently analysed half of the notes sheets each. Pseudonyms have been created for each participant.

\section{Results}

Mario described what he observed and assessed how effectively his fellow student undertook the task:

Observation of student ODP carrying out a scenario, pre-op check. ODP gave good explanation, was calm and reassuring; [theatre] check-in was relatively good, however although diabetic status and medication was checked patient's BM [blood sugar] wasn't done or medication for depression checked (Mario).

Mo provided a clear identification of personal learning needs arising from her engagement in simulation by providing an action plan that clearly linked the experience to her personal learning needs:

Learnt that we need to approach this task [theatre checklist] holistically and put the patient first whilst being safe. Thinking about the holistic approach to care I will in the future ask about the patient's arrangements after surgery. Don't make this a tick-box exercise; use it as an opportunity to reassure the patient. When I am back in placement I will look at the patient as a whole and have a plan in my head on what I need to do before getting to the patient (Mo).

Mo's reflection suggests that engagement within simulation is a sufficiently vivid experience to prompt students to consider the application of the learning to their next clinical placement. Dunn et al.'s (2016) small phenomenological study, which used focus groups to explore the lived experience of ODP students, highlighted how engagement in simulation enabled them to feel more confident whilst on placement. 
Mario considered the actions of others in comparison to himself and what actions he would take. A clear and specific action plan was suggested by Mario which he linked to his personal learning needs:

Observed student ODP carrying out a scenario... I was an observer. Patient said she thought she understood what was going on. The student didn't give a clear explanation and confirm it was what the patient expected. Observations taken and consent, checking-in other than that were good. Made me look at how I am in practice. How I could do things differently myself: Improve my 'checking-in a patient' skills. Speak to my mentors about areas in which I possibly need to improve, look at a hospital policy of what is expected with regards to checking-in a patient and make improvements (Mario).

Jan detailed specifically what she had learnt from playing the role of the ODP in terms of her overall performance and provided quite a detailed personal action plan based on her practice during the scenario:

I learnt how to assess a patient before surgery. I learnt how to check the consent with the patient and take into consideration mental, social, physical needs. I was responsible for flagging any concerns I might have about suitability for surgery. [Things I did] well were I managed to create a calm environment and ensure patient felt safe. I checked all the relevant details i.e. patient ID, fasting status, consent, etc. I also checked how the patient was feeling (mental status). [Things I did] not so well were I didn't check allergy [wrist] band. I didn't ask the pregnancy question sensitively. I've learnt that apart from the usual questions asked and answered it is important to try and see signs of things not so obvious i.e. mental state, fasting status. I think it would be important for me to learn more about pre-assessment in different situations. I [need to] break down the scenario and read up on the different aspects of the patient's history. I will read up on pre-assessment and the different outcomes and decisions that need to be made. I will be more focused on using my observational skills to look for signs of issues with the patient and to try and make the patient feel I am engaged, present and sensitive to their needs (Jan).

Jan's piece of reflection demonstrates how a relatively structured simulation scenario such as the completion of a theatre checklist requires the practitioner to engage in a wider holistic assessment that necessitates clinical decision-making. In Bucknall et al.'s (2016) study, which used video to 'cue' participants to recall the rationale for their decision-making during simulation, eleven typologies of decisions were identified including information seeking, patient assessment, and escalation (as Jan touched on in her reflection).

In comparison to the midwifery students, more ODP students were assessed as completing pure description, although most were assessed as descriptive reflectors, as illustrated in Figure 2's pie chart.

Figure 2: Depth of reflection within notes sheets - ODP student study

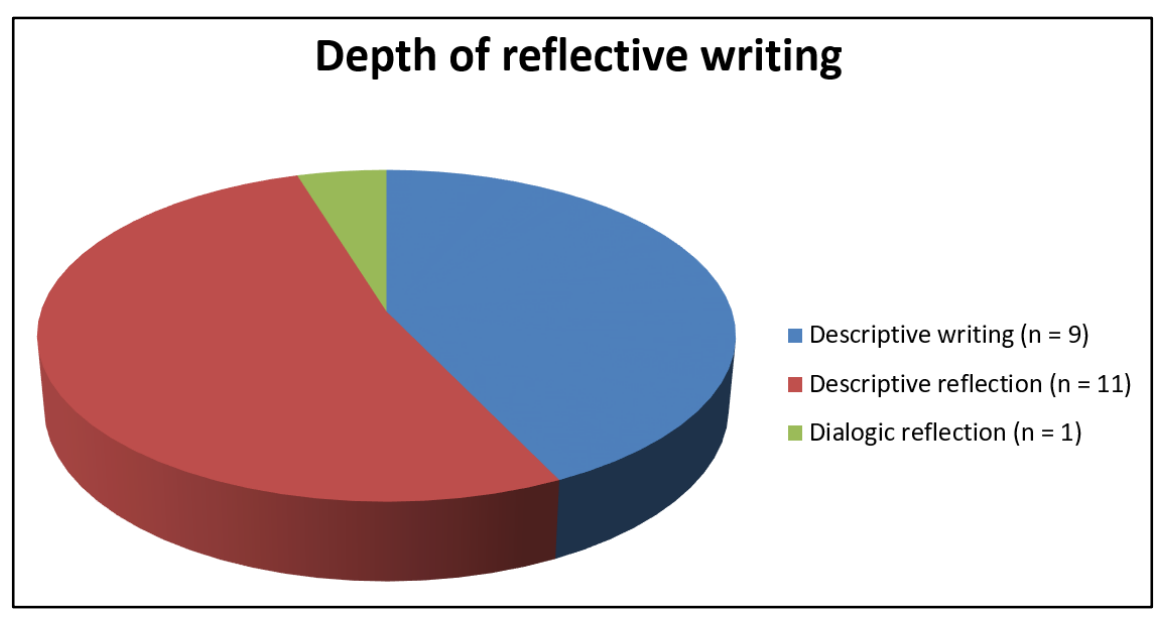




\section{Discussion}

The findings from this study suggest that the notes sheet is effective in capturing pre-briefing and debriefing by students, as not only did students take notes during each stage of the simulation but notes were concordant with the SBAR structure and the model of reflection provided. This finding is particularly significant in relation to the ODP students as they took part in two cycles that featured the same simulation scenario.

Additionally, the findings from this study suggest that 39 students who engaged in a clinical simulation engaged in the process of reflection at descriptive-reflector level or above. This finding may indicate the ability of the participants to produce written work (in terms of reflective depth) based on the stage of their studies, as participants comprised first-year midwifery and second-year ODP students. Fifteen of the total number of participants produced written work which was assessed as 'pure description'. However, 34 students were assessed as descriptive reflectors, and five students were assessed as dialogic reflectors.

Of perhaps greater interest is the extent to which documentary evidence from the reflective accounts pointed to some of the key educational outcomes which are said to justify clinical simulation within the literature, such as assimilation of clinical information, clinical decision-making, self-assessment, and selfefficacy. Assimilation of clinical information, as was highlighted in the reflective account written by Rosamund, suggested that the notes sheet performed as well as the REsPOND model evaluated by Lavoie et al. (2017). Self-assessment was evident in Dina's account where she highlighted the need for a systematic approach to emergency situations, which concurs with the findings of Jensen's (2013) study, which asserted the importance of students being given the opportunity to self-assess their clinical reasoning abilities. Finally, self-efficacy was alluded to by Meena in her discussion of the benefit of simulation which reflects the findings of Pike \& O'Donnell's (2010) study in relation to the value of simulation in enabling students to evaluate the most effective communication strategies.

One of the benefits of utilising SBAR and giving students the opportunity to take notes from oral debriefing is that it appeared to drive-reflective writing as evident from the documentary analysis. Additionally, familiarity with SBAR reinforces its primary purpose as a communication tool for the efficient and effective reporting of clinical information (Thomas et al., 2009) that enhances students' confidence and empowerment in reporting (Gore et al., 2015). The sheet may enable academic staff to identify disparities between students' self-assessed clinical competency and decision-making and their actual performance and clinical outcomes observed during the clinical simulation. For example, Jensen's (2013) study suggested that students rated themselves higher than academic staff on clinical reasoning behaviours during simulated patient care and recommended formal feedback in addition to selfassessment to promote a more reliable judgement of a student's clinical reasoning abilities, as indicated by the reflective account written by Jan. The examination of a reflective account alone by an academic in order to make such a judgement could be argued to be 'student entrapment'. However, the inclusion of personal development planning as a forward-facing, future-referenced activity should provide a measure of assurance for students who become aware, or who are made aware that their practice, judgement or clinical reasoning is sub-optimal. Interestingly, Fero et al.'s (2010) study identified that 75\% of nursing students within their final term of study were unable to perform to the expected level in terms of synthesising and reporting clinical information whilst in simulation. The use of a tool which may provide clues to a student's performance in respect of receiving, processing and applying information and then reflecting on the entire experience could provide simulation facilitators with a supportive and appreciative basis for challenging discussions with weak students following clinical simulation (Shinnick et al., 2011) as suggested by the reflective account written by Gemma.

\section{Limitations}

One of the obvious limitations of the study is the relatively small size of participant groups, although the study team attempted to minimise the effect of this by repeating the same scenario with the smaller ODP participant group. Additionally, it could be argued that coming to a conclusion about the value of a student's reflective account based on depth of reflective writing alone obviates the actual value of the learning experience. 


\section{Conclusions}

This study has demonstrated evidence of the utility and value of SBAR, Driscoll's (2007) model of reflection and oral debriefing following a period of simulation to enable healthcare students to identify personal learning points that can feed into development planning. One intrinsic value of the notes sheet is that it requires academic staff to ensure that simulation sessions are commensurate with the SBAR structure and therefore clinically authentic. Additionally, oral debriefing, when placed at the centre of the simulation process and delivered appropriately (Wickers, 2010), acts as a catalyst for reflective writing. Consequently, this requires facilitators to be skilled in simulation debriefing. As debriefing is not currently included in postgraduate certificate in learning and teaching programmes for new academics, it is incumbent on clinical simulation teams to provide training and support for new academic staff. The team is exploring the use of an electronic version of the notes sheet using PebblePad® which would enable students to generate evidence of their engagement in clinical skills and clinical simulation sessions for electronic portfolios and to discuss development needs during meetings with personal academic tutors. The sheet includes a simple structure for oral debriefing by facilitators ahead of the internal dialogue that engagement in reflection, as reflected in the findings of this study, clearly initiates.

\section{References}

Alinier, G. (2003). Nursing students' and lecturers' perspectives of objective structured clinical education incorporating simulation. Nurse Education Today, 23(6), 419-426. https://doi.org/10.1016/S0260-6917(03)00044-3

Brush, T. A, \& Saye, J. W. (2002). A summary of research exploring hard and soft scaffolding for teachers and students using a multimedia supported learning environment. Journal of Interactive Online Learning, 1(2), 1-12. https://www.ncolr.org/jiol/issues/pdf/1.2.3.pdf

Bucknall, T. K., Forbes, H., Phillips, N. M., Hewitt, N. A., Cooper, S., \& Bogossian, F. (2016). An analysis of nursing students' decision-making in teams during simulations of acute patient deterioration. Journal of Advanced Nursing, 72(10), 2482-2494. https://doi.org/10.1111/jan.13009

Cantrell, M. A. (2008). The importance of debriefing in clinical simulations. Clinical Simulation in Nursing, 4(2), e19-e23. https://doi.org/10.1016/j.ecns.2008.06.006

Coffey F., (2015). Learning by simulation - is it a useful tool for midwifery education? New Zealand College of Midwives Journal, 51, 30-36. https://doi.org/10.12784/nzcomjn151.2015.5.30-36

Cooper, S., Cant, R., Porter, J., Bogossian, F., McKenna, L., Brady, S. M., \& Fox-Young, S. (2012). Simulation based learning in midwifery education: A systematic review. Women and Birth, 25(2), 64-78. https://doi.org/10.1016/j.wombi.2011.03.004

Crotty, M. (1998). The foundations of social research: Meaning and perspective in the research process. Sage.

Driscoll, J. (2007). Practising clinical supervision: A reflective approach for healthcare professionals (2nd ed.). Elsevier.

Dunn, L., Tyas, M., \& Garside, J. (2016). Preregistration students' reactions to simulation as an education approach within an operating department practitioner curriculum: A qualitative review. Clinical Simulation in Nursing, 12(5), 147-151. https://doi.org/10.1016/j.ecns.2015.12.012

Fero, L. J., O’Donnell, J. M., Zullo, T. G., DeVito Dabbs, A., Kitutu, J., Samosky, J. T., \& Hoffman, L. A. (2010). Critical thinking skills in nursing students: Comparison of simulation-based performance with metrics. Journal of Advanced Nursing, 66(10), 2182-2193. https://doi.org/10.1111/j.1365-2648.2010.05385.x 
Forneris, S. G, Neal, D. O., Tiffany, J., Kuehn, M. B., Meyer, H. M., Blazovich, L. M., Holland, A. E., \& Smerillo, M. (2015). Enhancing clinical reasoning through simulation debriefing: A multisite study. Nursing Education Perspectives, 36(5), 304-310. https://doi.org/10.5480/15-1672

Gore, A., Leasure, A. R., Carithers, C., \& Miller, B. (2015). Integrating hand-off communication into undergraduate nursing clinical courses. Journal of Nursing Education and Practice, 5(4), 70-76. https://doi.org/10.5430/jnep.v5n4p70

Gray, D. E. (2014). Doing research in the real world (3rd ed.). Sage.

Hatton, N., \& Smith, D. (1995). Reflection in teacher education: Towards definition and implementation. Teaching and Teacher Education, 11(1), 33-49. https://doi.org/10.1016/0742-051X(94)00012-U

Jensen, R. (2013). Clinical reasoning during simulation: Comparison of student and faculty ratings. Nurse Education in Practice, 13(1), 23-28. https://doi.org/10.1016/j.nepr.2012.07.001

Kember, D., McKay, J., Sinclair, K., \& Wong, F. K. Y. (2008). A four-category scheme for coding and assessing the level of reflection in written work. Assessment \& Evaluation in Higher Education, 33(4), 369-379. https://doi.org/10.1080/02602930701293355

Lavoie, P., Pepin, J., \& Cossette, S. (2017). Contribution of a reflective debriefing to nursing students' clinical judgment in patient deterioration simulations: A mixed-methods study. Nurse Education Today, 50, 51-56. https://doi.org/10.1016/j.nedt.2016.12.002

Lewis, D. Y., \& Ciak, A. D. (2011). The impact of a simulation lab experience for nursing students. Nursing Education Perspectives, 32(4), 256-258. https://doi.org/10.5480/1536-5026-32.4.256

Mackey, S., Tan, K. K., Ignacio, J., Palham, S., Dawood, R. B. M., \& Liaw, S. Y. (2014). The learning experiences of senior student nurses who take on the role of standardised patient: A focus group study. Nurse Education in Practice, 14(6), 692-697. https://doi.org/10.1016/j.nepr.2014.10.003

McCulloch, G. (2012). Documentary methods. In J. Arthur, M. Waring, R. Coe, \& L. V. Hedges (Eds.), Research methods \& methodologies in education (pp. 210-214). Sage.

Meakim, C., Boese, T., Decker, S., Franklin, A. E., Gloe, D., Lioce, L., Sando, C. R., \& Borum, J. C. (2013). Standards of best practice: Simulation standard I: Terminology. Clinical Simulation in Nursing, 9(6), S3-S11. https://doi.org/10.1016/j.ecns.2013.04.001

Moon, J. A. (2004). A handbook of reflective and experiential learning: Theory and practice. RoutledgeFalmer.

Muldoon, K., Biesty, L., \& Smith, V. (2014). 'I found the OSCE very stressful': Student midwives' attitudes towards an objective structured clinical examination (OSCE). Nurse Education Today, 34(3), 468-473. https://doi.org/10.1016/j.nedt.2013.04.022

NHS Improvement. (2018). Online library of Quality Service Improvement and Redesign Tools: SBAR Communication tool. ACT Academy. https://improvement.nhs.uk/documents/2162/sbarcommunication-tool.pdf

Orland-Barak, L. (2005). Portfolios as evidence of reflective practice: What remains 'untold'. Educational Research, 47(1), 25-44. https://doi.org/10.1080/0013188042000337541

Pike, T., \& O’Donnell, V. (2010). The impact of clinical simulation on learner self-efficacy in preregistration nursing education. Nurse Education Today, 30(5), 405-410. https://doi.org/10.1016/j.nedt.2009.09.013

Plack, M. M, Driscoll, M., Blissett, S., McKenna, R., \& Plack, T. P. (2005). A method for assessing reflective journal writing. Journal of Allied Health, 34(4), 199-208. https://www.ingentaconnect.com/contentone/asahp/jah/2005/00000034/00000004/art00004 
Shinnick, M. A., Woo, M., Horwich, T. B., \& Steadman, R. (2011). Debriefing: the most important component in simulation? Clinical Simulation in Nursing, 7, e105-e111.

https://doi.org/10.1016/j.ecns.2010.11.005

Thomas, C. M, Bertram, E., \& Johnson, D. (2009). The SBAR communication technique: Teaching nursing students professional communication skills. Nurse Educator, 34(4), 176-180. https://doi.org/10.1097/NNE.0b013e3181aaba54

Wickers, M. P. (2010). Establishing the climate for a successful debriefing. Clinical Simulation in Nursing, 6(3), e83-e86. https://doi.org/10.1016/j.ecns.2009.06.003

Wong, F. K. Y., Kember, D., Chung, L. Y. F., \& Yan, L. (1995). Assessing the level of student reflection from reflective journals. Journal of Advanced Nursing, 22(1), 48-57.

https://doi.org/10.1046/j.1365-2648.1995.22010048.x 